University of Wollongong

Research Online

Faculty of Engineering - Papers (Archive)

Faculty of Engineering and Information

Sciences

$1-1-2008$

\title{
Physiochemical characterizations of hydroxyapatite extracted from bovine bones by three different methods: extraction of biologically desirable Hap
}

Nasser A. M Barakat

Chonbuk National University

K. A. Khalil

Chonbuk National University

Faheem A. Sheikh

Chonbuk National University

A. M. Omran

Chonbuk National University

Babita Gaihre

University of Wollongong, babita@uow.edu.au

See next page for additional authors

Follow this and additional works at: https://ro.uow.edu.au/engpapers

Part of the Engineering Commons

https://ro.uow.edu.au/engpapers/1086

\section{Recommended Citation}

Barakat, Nasser A. M; Khalil, K. A.; Sheikh, Faheem A.; Omran, A. M.; Gaihre, Babita; Khil, Soeb M.; and Kim, Hak Yong: Physiochemical characterizations of hydroxyapatite extracted from bovine bones by three different methods: extraction of biologically desirable Hap 2008, 1381-1387.

https://ro.uow.edu.au/engpapers/1086

Research Online is the open access institutional repository for the University of Wollongong. For further information contact the UOW Library: research-pubs@uow.edu.au 
Authors

Nasser A. M Barakat, K. A. Khalil, Faheem A. Sheikh, A. M. Omran, Babita Gaihre, Soeb M. Khil, and Hak Yong Kim 


\title{
Physiochemical characterizations of hydroxyapatite extracted from bovine bones by three different methods: Extraction of biologically desirable HAp
}

\author{
Nasser A.M. Barakat ${ }^{\text {a,b }}$, K.A. Khalil ${ }^{\text {, }}$, Faheem A. Sheikh ${ }^{\text {c }}$, A.M. Omran ${ }^{\text {c }}$, Babita Gaihre ${ }^{\text {, }}$ \\ Soeb M. Khil ${ }^{\mathrm{d}}$, Hak Yong Kim ${ }^{\mathrm{a}, \mathrm{d}, *}$ \\ a Center for Healthcare Technology Development, Chonbuk National University, Jeonju 561-756, Republic of Korea \\ b Chemical Engineering Department, Faculty of Engineering, El-Minia University, El-Minia, Egypt \\ c Department of Bionano System Engineering, College of Engineering, Chonbuk National University, Jeonju 561-756, Republic of Korea \\ d Department of Textile Engineering, Chonbuk National University, Jeonju 561-756, Republic of Korea
}

\section{A R T I C L E I N F O}

\section{Article history:}

Received 24 November 2007

Accepted 16 March 2008

Available online 25 March 2008

\section{Keywords:}

Carbonated hydroxyapatite

Bovine bone

Subcritical water

Alkaline hydrolysis

Thermal elimination

Physiochemical characterization

\begin{abstract}
A B S T R A C T
In the present study, subcritical water and alkaline hydrolysis methods are proposed methodologies for extraction of natural hydroxyapatite bioceramic from bovine bone. In these processes, the bovine bones powder were treated by high pressure water at $250{ }^{\circ} \mathrm{C}$ for $1 \mathrm{~h}$ and $25 \%$ (wt) sodium hydroxide at $250{ }^{\circ} \mathrm{C}$ for $5 \mathrm{~h}$, respectively. Also the conventional calcination methodology has been utilized as well $\left(T=850^{\circ} \mathrm{C}\right.$ for $\left.1 \mathrm{~h}\right)$. The obtained apatites from the three treatment processes have been characterized by powder X-ray diffraction analysis (XRD), Fourier transform infrared spectroscopy (FT IR), transmission electron microscopy (TEM), thermal gravimetric analysis (TGA), electron scanning microscopy (SEM), energy dispersive X-ray analysis (EDX) and field emission scanning electron microscopy (FE SEM). FT IR and XRD results affirmed that both the proposed methods and the traditional one can eliminate the collagen and other organic materials present in the bovine bones. The physiochemical characterizations for the obtained apatites have proved that the subcritical water and the alkaline hydrolysis relatively preserve the carbonate content present in the biological apatite, so they yield carbonated hydroxyapatite which is medically preferable. While, the thermal process produces almost hydroxyapatite carbonate-free.
\end{abstract}

(c) 2008 Elsevier B.V. All rights reserved.

\section{Introduction}

Hydroxyapatite (HAp) is widely utilized in medical fields, due to its good biocompatibility, bioactivity, high osteoconductive and/or osteoinductive nontoxicity, noninflammatory behavior and nonimmunogenicity properties $[1,2]$. Therefore, different production methods were reported such as mechanochemistry [3,4], ultrasonic irradiation [5], microwave irradiation [6,7], sol-gel [8-11], chemical precipitation [12,13], hydrothermal method [14-16], hydrolysis [17], microemulsion [18-20], and emulsion liquid membrane [21]. The synthesized HAp does not have adequate biological properties as the natural apatite existing in bones. To enhance its biological properties, substitution of some foreign ions/groups was employed [22]. Coupled substitutions frequently occur where one ion is replaced by another of the same sign but of different charge. Neutrality is maintained by substitution of ions with dissimilar charges or vacancies elsewhere [23]. The carbonate substitution is of particular importance because the mineral phase of

\footnotetext{
* Corresponding author. Center for Healthcare Technology Development, Chonbuk National University, Jeonju 561-756, Republic of Korea. Tel.: +82 63270 2351; fax: +82 632702348.

E-mail addresses: nasbarakat@yahoo.com (N.A.M. Barakat), khy@chonbuk.ac.kr (H.Y. Kim).
}

bone, dentin and enamel mainly consists of carbonated hydroxyapatite (CHAp), containing 4-6 wt.\% carbonate [22,23].

To produce biologically preferable HAp and avoiding the sophisticated procedures used in the synthesizing of HAp, some researchers have turned into extraction of natural HAp from bio-wastes (usually via calcination). Extraction of HAp from the bio-wastes is a biologically safe (no foreign chemicals are utilized) and economically desirable process especially with the increasing world demand of HAp bioceramics. Many bio-wastes have been exploited for such purpose, for instance fish bones [24], bovine bones [25] and bones and teeth of pig [26]. Unfortunately, it was reported that most of the carbonate groups present in the carbonated hydroxyapatite are eliminated by heating which affects the biological properties of the obtained apatite extracted by the thermal process [22,27]. Therefore, searching for a new method to extract natural carbonated hydroxyapatite from the bovine bones rather than hydroxyapatite devoid of carbonate was the main goal of the present study. Natural apatites have been extracted from the bovine bones by subcritical water extraction and alkaline hydrothermal processes as new proposed methods. Also, the conventional thermal method was applied to optimize the three utilized methods.

Bone does have $65-70 \%$ hydroxyapatite and $30-35 \%$ organic compounds (on a dry weight basis). Collagen is the main organic compound present in the natural bone (95\%), besides there are other organic compounds existing in small concentrations such as chondroitin 
sulfate, keratin sulfate and lipids (e.g. phospholipids, triglycerides, fatty acids, cholesterol,...etc) [28].

The first proposed extraction method in this study is the hydrothermal alkaline hydrolysis this process was exploited to hydrolyze collagen-like protein (i.e. keratin) in an autoclave [29] or by microwaves [30]. In this study, this method has been applied to hydrolyze collagen and other organic compounds using an autoclave. Subcritical water or pressurized low polarity water (PLPW) is a promising extraction and fractionation technique that uses hot liquid water under pressure. Working temperatures below the critical value of water $\left(379^{\circ} \mathrm{C}\right)$ but above $100{ }^{\circ} \mathrm{C}$ are usually employed. Increasing the water temperature causes changes in solvent polarity, surface tension, and viscosity [31]. Water dielectric constant is also reduced with increasing temperature resulting in reduction of polarity. Therefore, the subcritical water has been invoked to dissolve many complicated organic compounds for example lignans, proteins and carbohydrates from flaxseed meal [32], anti-cancer damnacanthal from roots of Morinda citrifolia [33], essential oils from coriander seeds [34] and saponins from cow cockle seed [35]. Hence, the PLPW has been utilized to pluck the collagen and other organic compounds out the bovine bones leaving the desired natural apatite. The third process utilized in this study is direct heating of the bovine bone to remove the organic compounds which can be thermally eliminated [24-26,36].

X-ray diffraction analysis (XRD) and Fourier transform infrared spectroscopy (FT IR) were exploited to identify the obtained solid materials after treatment of the bovine bones by the three aforementioned extraction processes. The obtained results were satisfactory; XRD and FT IR analyses confirmed that all the three processes have the ability to extract pure HAp from the bovine bones. Investigation of hydroxyl and carbonate groups in the obtained apatites was achieved by IR spectroscopy and thermal gravimetric analysis (TGA). IR spectroscopy is a powerful method in ionic investigation and has been used extensively in phosphate minerals research [37-39]. Transmission Electron microscopy (TEM), electron scanning microscopy (SEM), energy dispersive X-ray analysis (EDX) and field emission scanning electron microscopy (FE SEM) were also utilized in the physiochemical characterization process for the obtained materials.

\section{Materials and methods}

\subsection{Bovine bone preparation}

The bovine bones were washed carefully with water and acetone to remove the fats or any other impurities. Then, the bones were dried at

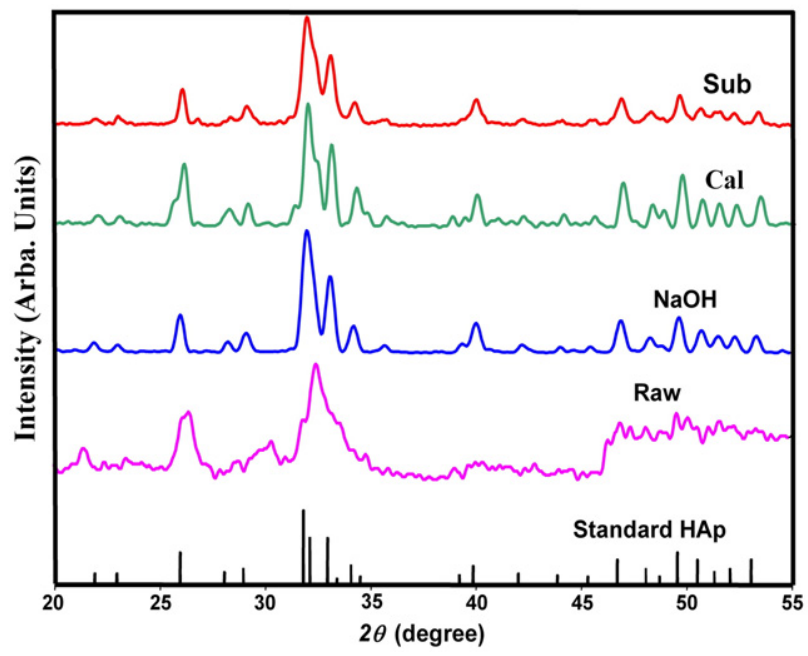

Fig. 1. XRD for the raw bovine bone (Raw) and the treated ones [bovine bone treated by $25 \% \mathrm{NaOH}$ solution at $250{ }^{\circ} \mathrm{C}$ for $5 \mathrm{~h},(\mathrm{NaOH})$; bovine bones treated by subcritical water at $250{ }^{\circ} \mathrm{C}$ for $1 \mathrm{~h},(\mathrm{Sub})$; bovine bones heated at $850{ }^{\circ} \mathrm{C}$ for $\left.1 \mathrm{~h},(\mathrm{Cal})\right]$.
Table 1

Planar spacings and intensities obtained from X-ray diffraction for the obtained ones from the proposed processes, the results are compared with the standard HAp (JCPDS)

\begin{tabular}{|c|c|c|c|c|c|c|c|c|}
\hline \multirow[t]{2}{*}{ (hkl) } & \multicolumn{4}{|l|}{$d(\mathrm{~nm})$} & \multicolumn{4}{|c|}{ Intensity } \\
\hline & JCPDS & Cal & $\mathrm{NaOH}$ & Sub & JCPDS & Cal & $\mathrm{NaOH}$ & Sub \\
\hline 002 & 0.3440 & 0.3411 & 0.3424 & 0.3424 & 40 & 52 & 31 & 44 \\
\hline 211 & 0.2814 & 0.2799 & 0.2795 & 0.2803 & 100 & 100 & 100 & 100 \\
\hline 112 & 0.2778 & 0.2704 & 0.2704 & 0.2712 & 60 & 67 & 63 & 61 \\
\hline 202 & 0.2631 & 0.2612 & 0.2616 & 0.2627 & 25 & 32 & 22 & 24 \\
\hline 310 & 0.2261 & 0.2252 & 0.2495 & 0.2255 & 20 & 27 & 25 & 23 \\
\hline 222 & 0.1943 & 0.1936 & 0.1936 & 0.1939 & 30 & 37 & 27 & 30 \\
\hline 213 & 0.1841 & 0.1934 & 0.1835 & 0.1835 & 40 & 36 & 30 & 33 \\
\hline 321 & 0.1806 & 0.1855 & 0.1797 & 0.1801 & 20 & 43 & 19 & 18 \\
\hline 004 & 0.1722 & 0.1710 & 0.1717 & 0.1717 & 20 & 25 & 14 & 19 \\
\hline Total error & & 0.14 & 0.064 & 0.048 & & 2.81 & 1.31 & 0.64 \\
\hline
\end{tabular}

$160{ }^{\circ} \mathrm{C}$ for $48 \mathrm{~h}$. The cleaned dried bones were grinded to particle size less than $450 \mu \mathrm{m}$.

\subsection{Subcritical water process}

Cylindrical hydrothermal stainless steel reactor with internal diameter of $6 \mathrm{~cm}$, external diameter of $7.4 \mathrm{~cm}$ and height of $15 \mathrm{~cm}$ was used in this process. The grinded bones were added to deionized water at solid to liquid ratio of 1:40. The mixture was placed in a Teflon crucible inside the stainless steel reactor. Nitrogen gas was used to remove the dissolved oxygen from the water and the atmosphere surrounding the Teflon crucible. The reactor was tightly sealed and heated in silicon oil bath at $250{ }^{\circ} \mathrm{C}$ for $1 \mathrm{~h}$. The reactor was cooled by quenching in big amounts of cold water. The obtained solid product was filtered, washed with distilled water and dried at $80{ }^{\circ} \mathrm{C}$ for $30 \mathrm{~min}$.

\subsection{Alkaline hydrothermal hydrolysis}

Sodium hydroxide (96.5\% purity, Duksan Pure Chem. Co. Ltd., South Korea) was used in the alkaline hydrothermal hydrolysis of collagen. The grinded bones were mixed with the sodium hydroxide solution with solid/liquid ratio of 1:50. The same aforementioned hydrothermal stainless steel reactor was exploited in this process. The reactor is tightly sealed and heated in a silicon oil bath. The hydrothermal experiment has been achieved via $25 \%$ (wt) sodium hydroxide solution concentration at a temperature of $250{ }^{\circ} \mathrm{C}$ for $5 \mathrm{~h}$.

\subsection{Thermal decomposition}

In the thermal decomposition process $1 \mathrm{~g}$ sample was placed in an open alumina crucible then heated in the furnace (Lenton Thermal Designs Ltd., South Korea). The sample was heated to $850{ }^{\circ} \mathrm{C}$ at heating rate of $10^{\circ} \mathrm{C} / \mathrm{min}$. The soaking time was $1 \mathrm{~h}$.

\subsection{Characterizations}

Fourier transform infrared (FT IR) spectra were recorded as $\mathrm{KBr}$ pellets using Varian FTS 1000 FT IR, Mid-IR spectral range, cooled DTGS detector, Scimitar series, Varian Inc. The spectra were analyzed by using Varian Resolution Pro version 4.0.5 from Varian. Thermal gravimetric have been achieved via Pyris1 TGA analyzer, PerkinElmer Inc., USA. Surface morphology was studied by JEOL JSM-5900 scanning electron microscope equipped with energy dispersive X-ray (EDX), JEOL Ltd., Japan. Field-emission scanning electron microscope (FE SEM) images have been obtained by an S-7400 instrument, Hitachi, Japan. The phase and crystallinity were characterized by using Rigaku X-ray diffractometer (Rigaku Co., Japan) with $\mathrm{Cu} \mathrm{K} \alpha\left(\lambda=1.54056 \mathrm{~A}^{\circ}\right)$ radiation over a range of $2 \theta$ angles from $20^{\circ}$ to $55^{\circ}$. Particle size and morphology were observed by JEOL JEM 


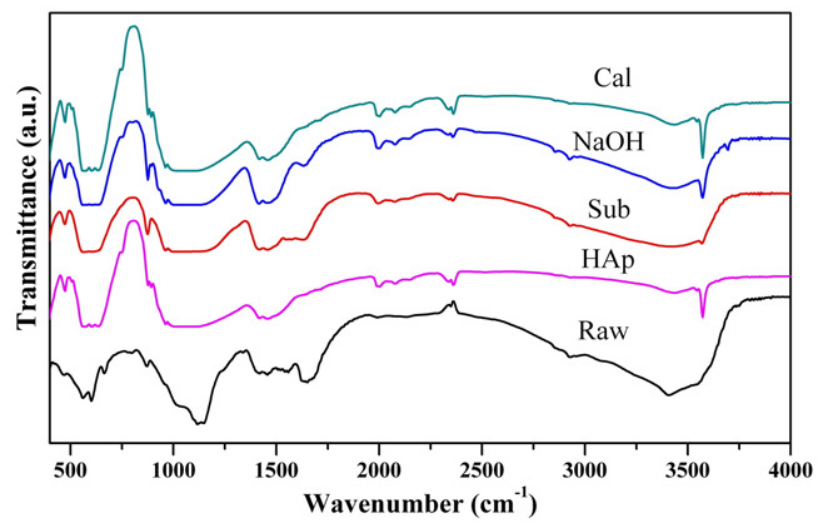

Fig. 2. FT IR for the pure hydroxyapatite (HAp), raw bovine bone (Raw), bovine bone treated by $25 \% \mathrm{NaOH}$ solution at $250{ }^{\circ} \mathrm{C}$ for $5 \mathrm{~h}$, $(\mathrm{NaOH})$, bovine bones treated by subcritical water at $250{ }^{\circ} \mathrm{C}$ for $1 \mathrm{~h}$ (Sub), and bovine bones heated at $850{ }^{\circ} \mathrm{C}$ for $1 \mathrm{~h}(\mathrm{Cal})$.

2010 transmission electron microscope (TEM) operating at $200 \mathrm{kV}$, JEOL Ltd., Japan.

\section{Results and discussion}

\section{1. $X R D$ results}

XRD analysis is a highly trustable technique utilized to investigate the crystalline compounds. Fig. 1 shows the XRD spectra of the raw bovine bone and the treated ones, i.e. calcined bone at $850{ }^{\circ} \mathrm{C}$ for $1 \mathrm{~h}$ (Cal), treated bone with subcritical water at $250{ }^{\circ} \mathrm{C}$ for $1 \mathrm{~h}$ (Sub), and treated bone with $25 \%$ (wt) sodium hydroxide solution at $250{ }^{\circ} \mathrm{C}$ for $5 \mathrm{~h}(\mathrm{NaOH})$. Hereafter, the used abbreviations in this figure will be used to refer the used extraction methods. The spectra have been validated via JCPDS standard HAp card [40,41]. As shown in this figure, all the peaks corresponding to the standard hydroxyapatite are obvious in the spectra of the treated bones. Therefore, it can be concluded that the proposed treatment processes have eliminated the collagen and organic compounds from the bovine bones and did not affect the molecular skeleton of the hydroxyapatite. For the raw bovine bone not all the standard hydroxyapatite peaks have been obtained due to presence of the fibrous collagen which disperses the $\mathrm{X}$-ray radiations.

It is noteworthy mentioning that, the intensities obtained in a case of utilizing the subcritical water extraction and the alkaline hydrolysis processes are relatively high. Table 1 shows the planar spacings (estimated by Bragg's law) and the intensities at the strongest peaks in the XRD spectra. These results have been compared with the standard HAp data (JCPDS); the error was estimated at each plane. As can be observed from the total error values, the HAp obtained by the subcritical water process (Sub) does have planar spacings and intensities very close to the standard HAp, next is the hydroxyapatite obtained by the alkaline hydrothermal process $(\mathrm{NaOH})$. That can draw the conclusion of: beside the thermal process which has been reported in many literatures the subcritical water extraction and the alkaline hydrothermal processes do have the ability of extracting the natural hydroxyapatite bioceramic from the bovine bone bio-waste.
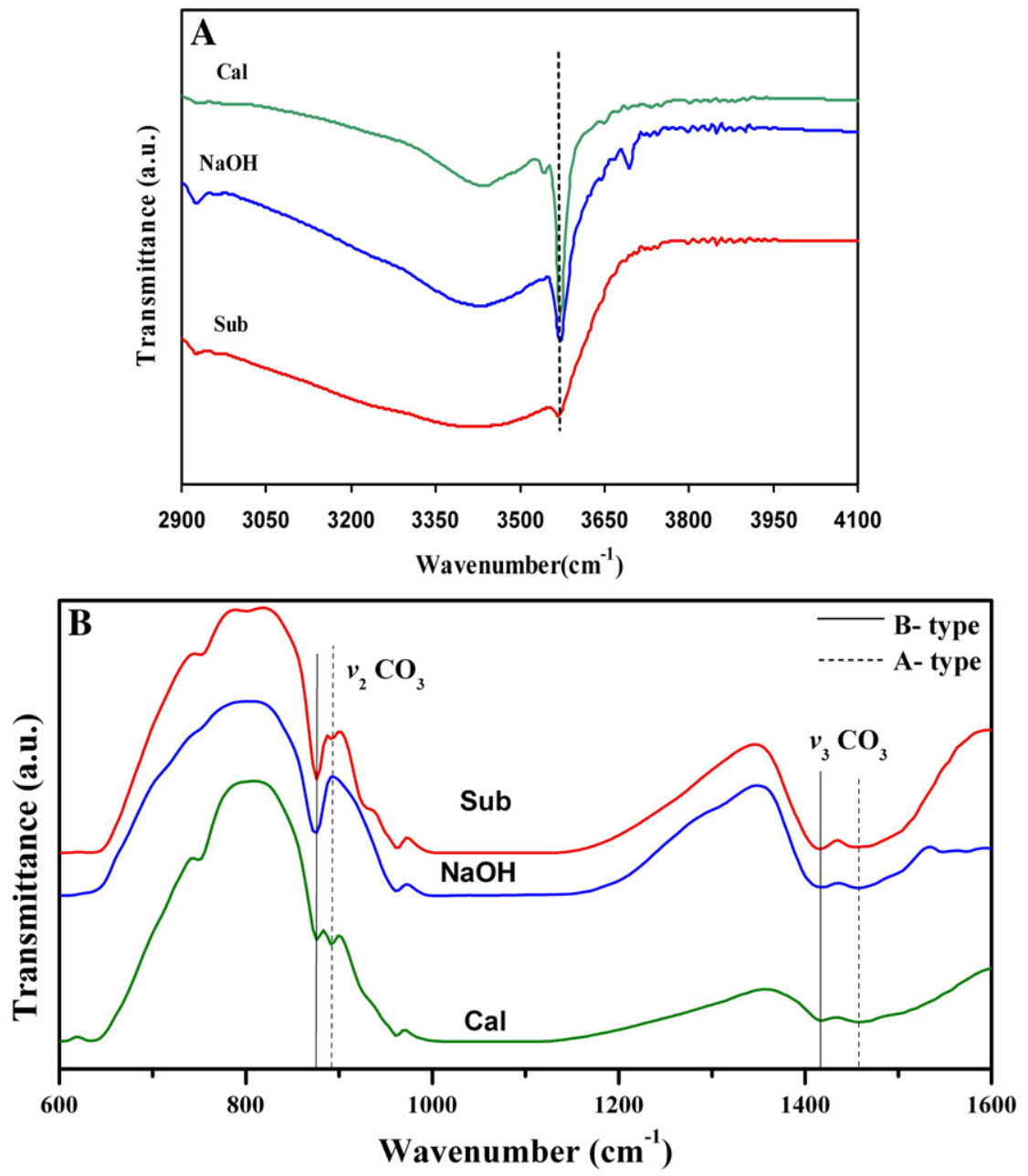

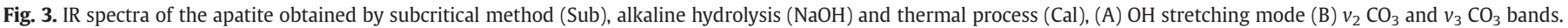




\subsection{FT IR results}

The bovine bone is an extracellular matrix mainly composed of HAp nanocrystals and collagen fibers. FT IR is a good tool for structural investigations because of the knowledge of the vibration origins of the amide bonds, the sensitivity of some of these band positions to conformation, and the possibility of predicting band positions for a given helical or extended conformation [42,43]. Fig. 2 shows the FT IR spectra of pure hydroxyapatite, the raw pulverized bovine bone and the treated bones. As shown from this figure, there are distinct differences between the spectra of the raw bovine bone and the treated ones. Moreover, the spectra of the treated bones are almost similar to the pure hydroxyapatite one which confirms the results obtained by XRD. In other words, the collagen and other organic compounds present in the bovine bones have been removed by the proposed treatment processes.

Presence of carbonate group in the carbonated hydroxyapatite is either at the phosphate tetrahedron (B-type) or at the hydroxyl site (A-type). Biological apatites do have both types however, B-type is more abundant [22]. The sharp band at $3572 \mathrm{~cm}^{-1}$ in all the spectra of Fig. $3 \mathrm{~A}$ is assigned to the $\mathrm{OH}$ stretching mode [23]. As shown in Figs. $3 \mathrm{~A}$ and $4 \mathrm{~A}$, the intensity of the $\mathrm{OH}$ stretching band is very small in the spectra of bovine bone treated by the subcritical water (Sub), moderate for the alkaline hydrothermal one and high in the spectra of calcined bovine bone (Cal). Nonetheless, the $\mathrm{OH}$ stretching peak is located at the same wavenumber for all the obtained apatites. Fleet and Liu [38] have recently reported that, decrease in the intensity of this band means increase in carbonate content and absence of structurally bound $\mathrm{OH}$. Fig. $3 \mathrm{~B}$ shows the bands of the carbonate $v_{2}$ $\mathrm{CO}_{3}$ and $v_{3} \mathrm{CO}_{3}$ for both types. As shown in this figure, both types of $v_{2}$ $\mathrm{CO}_{3}$ and $v_{3} \mathrm{CO}_{3}$ are present in the obtained apatites, however, A-type is meager and mainly exists in the apatite obtained by the calcination process. From Fig. 4B, one can say all the obtained apatites have B-type carbonate especially the apatites obtained by the subcritical water and alkaline hydrothermal processes. From Fig. 4C, it is noticeable that Atype carbonate mainly exists in the apatite obtained by the calcination process and such type is scarce in the apatite obtained by the subcritical water extraction method. Nevertheless, FT IR is not a quantitative analysis technique so, we cannot affirm which process produces high carbonate content apatite.

\subsection{Thermal gravimetric analysis}

Fig. 5A shows the thermal gravimetric analysis for the obtained apatites and the raw bovine bone. As shown in this figure, the weight losses at a temperature of $800{ }^{\circ} \mathrm{C}$ were $1.1,2.7$, and $4.67 \%$ for the apatite obtained by calcination, alkaline hydrothermal and subcritical processes, respectively. However, it was $32.9 \%$ for the raw bones. Fig. 5B shows the first derivative of the TG curves of the obtained apatites. According to the peaks that appeared in the first derivative curves (Fig. 5B), the weights losses occurred in the obtained apatites can be explained as follow:

At almost $50{ }^{\circ} \mathrm{C}$, a weight loss occurs due to evaporation of residual water (moisture). This loss appears as peaks in the first derivative curve of the obtained apatites by subcritical and alkaline hydrothermal processes. However, it does not appear in the apatite obtained by calcination because it is totally dry. At about $190{ }^{\circ} \mathrm{C}$ and $340{ }^{\circ} \mathrm{C}$, there are small and big peaks in the first derivative curve of the apatite obtained by calcination, these peaks accompanying weight losses of 0.4 and $0.9 \%$, respectively. These losses might refer to the dehydration of ions $\mathrm{HPO}_{4}^{-2}$ according to the following reaction [44]:

$2 \mathrm{HPO}_{4}^{-2} \rightarrow \mathrm{P}_{2} \mathrm{O}_{7}^{-4}+\mathrm{H}_{2} \mathrm{O}$

Moreover, since the FT IR spectra (Fig. 3B, Fig. 4B and C) indicated this apatite has A-type carbonate this content of $\mathrm{CO}_{3}^{-2}$ ions might react
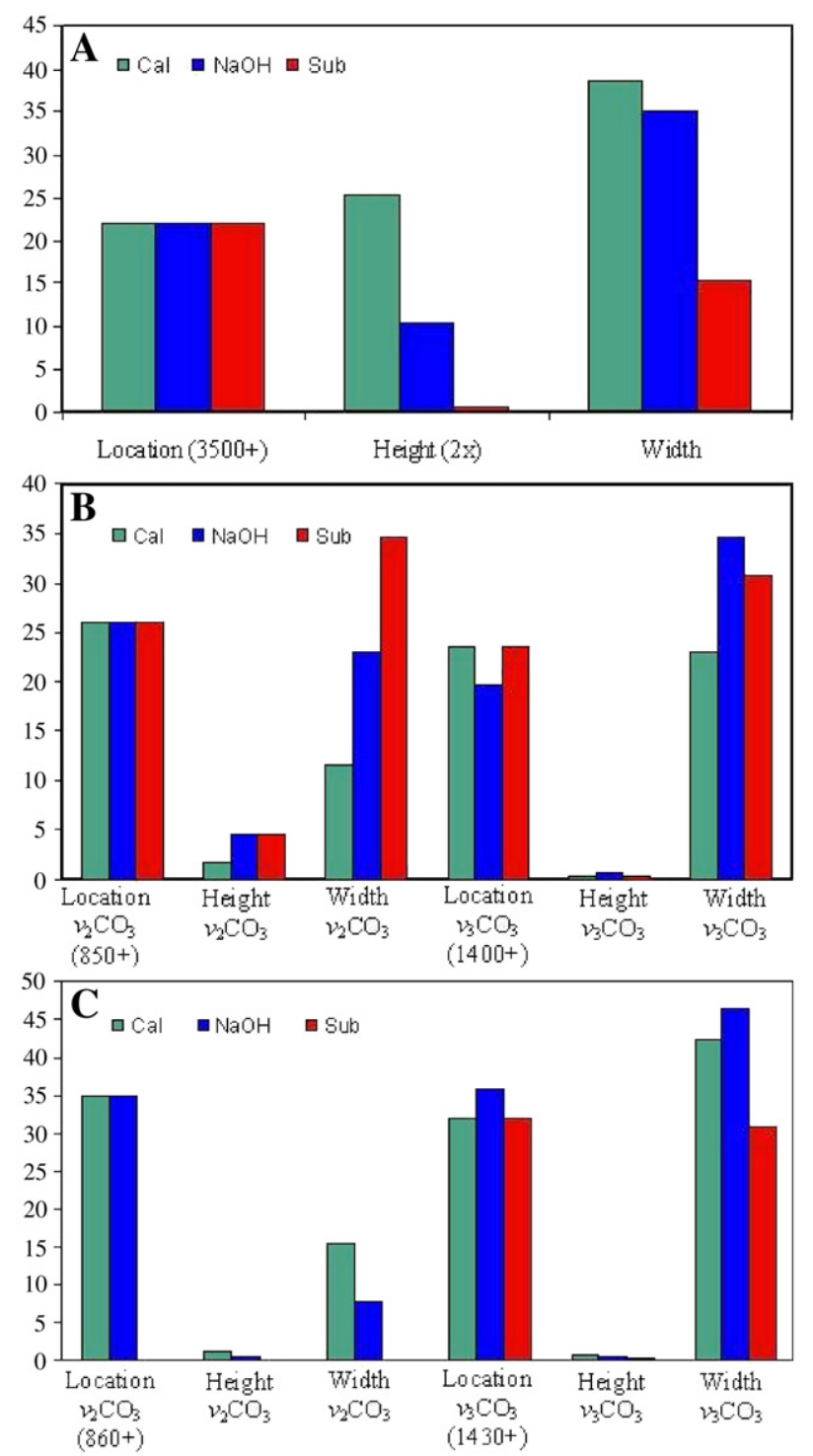

Fig. 4. Location, height and width of $\mathrm{OH}$ peak (A), Location, height and width of $v_{2} \mathrm{CO}_{3}$ and $v_{3} \mathrm{CO}_{3}$ B-type (B), A-Type (C).

with $\mathrm{HPO}_{4}^{-2}$ ions. The reaction can be carried out according to this way:

$\mathrm{CO}_{3}^{-2}+2 \mathrm{HPO}_{4}^{-2} \rightarrow \mathrm{CO}_{2}+2 \mathrm{PO}_{4}^{-3}+\mathrm{H}_{2} \mathrm{O}$

Also, as shown in Fig. 5B the first derivative curve of the apatite obtained by calcination has no significance beak after $360{ }^{\circ} \mathrm{C}$. Therefore, according to the FT IR and TGA results, one can say the apatite obtained by calcination process has very small carbonate content (mainly A-type). This carbonate content liberates at relatively low temperature.

In case of the apatite obtained by the subcritical water, the weight loss is relatively high compared with the other apatites (4.67\%). There are two broad peaks at 210 and $390{ }^{\circ} \mathrm{C}$, these peaks might be due to reactions 1 and 2 , respectively. Also, there is a strong peak at $733^{\circ} \mathrm{C}$. This peak has been investigated in a previous work [44], it is due to the presence of B-type carbonate. At such temperature, the following reaction occurs:

$\mathrm{P}_{2} \mathrm{O}_{7}^{-4}+\mathrm{CO}_{3}^{-2} \rightarrow 2 \mathrm{PO}_{4}^{-3}+\mathrm{CO}_{2}$ 

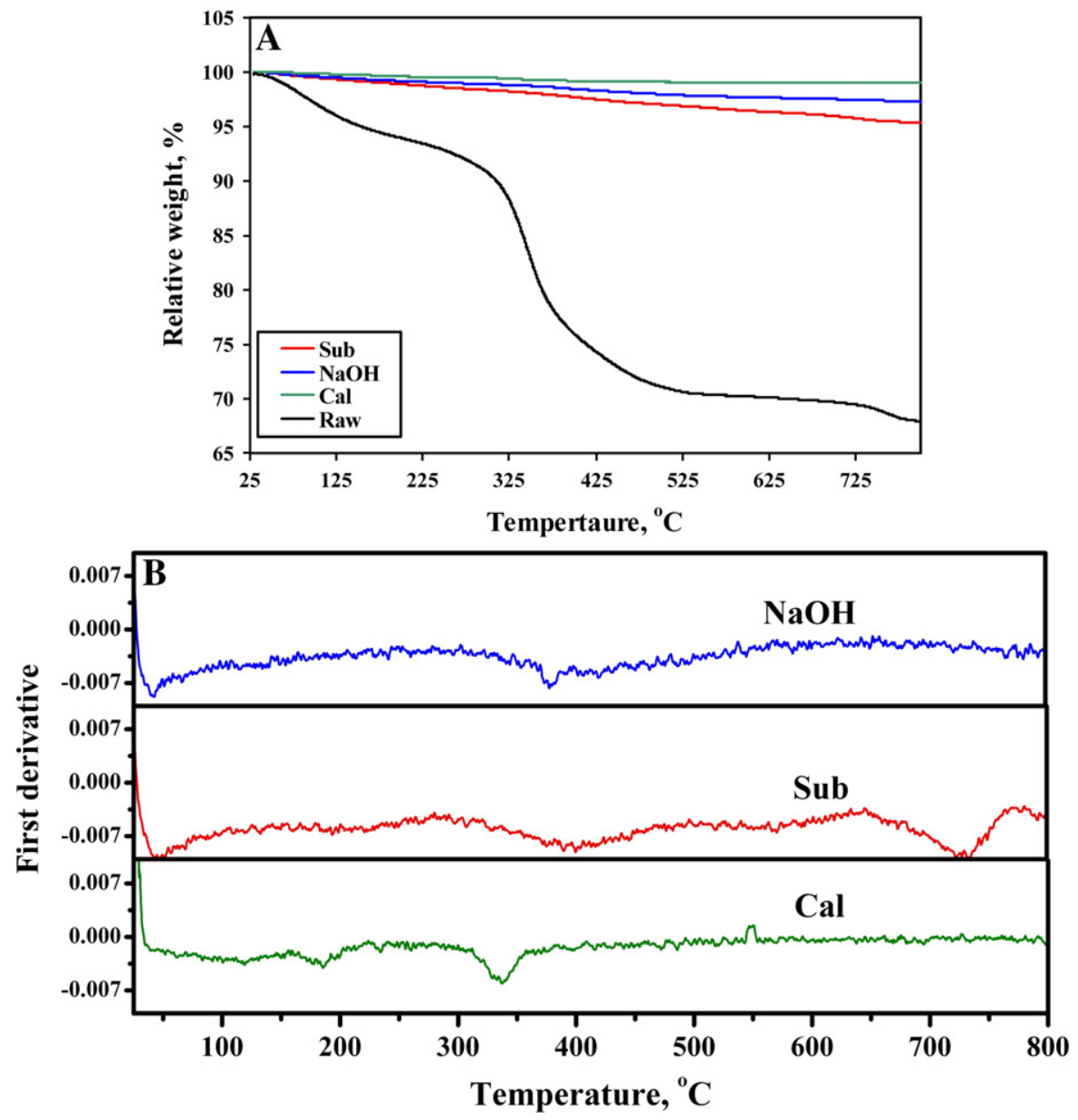

Fig. 5. (A) Thermal gravimetric for the apatite obtained by subcritical method (Sub), alkaline hydrolysis (NaOH), thermal process (Cal), and raw bone (Raw). (B) First derivative.

Therefore, according to the FT IR, the weight loss, and the strong peak in the first derivative curve (at $733^{\circ} \mathrm{C}$ ) can be concluded that, the subcritical water extraction process maintains most of the B-type carbonate present in the biological hydroxyapatite and almost eliminates A-type. However, since the B-type has more concentration in the biological apatite, the total carbonate content in the obtained apatite via this methodology is relatively high.

The apatite obtained by the alkaline hydrothermal process loses $2.7 \%$ from its weight and has a peak at $370{ }^{\circ} \mathrm{C}$ in the first derivative curve. This peak is due to the liberation of the carbonate according to reaction 2 especially this apatite has considerable amount of carbonate as shown in Figs. 3B, 4B and C. Also, a broad peak begins at almost $720^{\circ} \mathrm{C}$ this might be due to the liberation of a scanty amount of B-type carbonate (reaction 3). Therefore, we can say that the apatite obtained by the alkaline hydrothermal process has moderate amount of carbonate in both types (A and B), however, the extraction strategy intensively affects the B-type carbonate content in the biological HAp.

\subsection{EDX results}

According to the chemical formula of the standard hydroxyapatite, the theoretical calcium to phosphorous molar ratio is approximately 1.67. EDX analysis for the obtained apatite was performed and the results are shown in Fig. 6. As shown in the figure, the $\mathrm{Ca} / \mathrm{P}$ ratio for the apatite obtained by the subcritical water and alkaline hydrothermal methods were 1.56 and 1.86 , respectively these values lie within the acceptable range for the hydroxyapatite [45]. Variation of these values than the standard HAp value might be due to implication of the carbonate group in the apatites obtained by those methods.
However, as a new evidence assuring that the apatite obtained by the calcination process being almost free of carbonate, the $\mathrm{Ca} / \mathrm{P}$ molar ratio of the apatite obtained by such process is very close to the standard one (i.e. 1.65).

\subsection{Transmission electron microscope (TEM)}

Fig. 7 shows the TEM results. As shown from this figure, the calcination process produced good crystallinity apatite (Fig. 7 Cal. B) since the atoms are arranged in parallel planes. The atoms are arranged in unique crystal lattice shape; the lattice shape of the standard hydroxyapatite (i.e. hexagonal [41]). However, the apatite particles obtained are not uniform as shown in Fig. 7 Cal. A. The atoms in the apatite obtained by the subcritical water extraction process have relatively good arrangements while, the particle size is small compared with the other processes (Fig. 7. Sub. A). Fig. 7. NaOH.A shows the TEM micrograph for the apatite obtained by alkaline hydrothermal process, as shown in this figure the obtained nanoparticles have nanorod shape. However, the obtained HAp has relatively bad crystallinity as shown in the selected area electron diffraction pattern for this apatite (Fig. 7 NaOH.B).

\subsection{SEM and FE SEM results}

SEM and FE SEM instruments have been invoked to know the morphology of the obtained apatites. Fig. 8 shows the morphology of the apatite obtained by the alkaline hydrothermal and the calcination process. As shown in this figure, the thermal decomposition gives big particle size apatite. Formation of the big particles in the thermal 

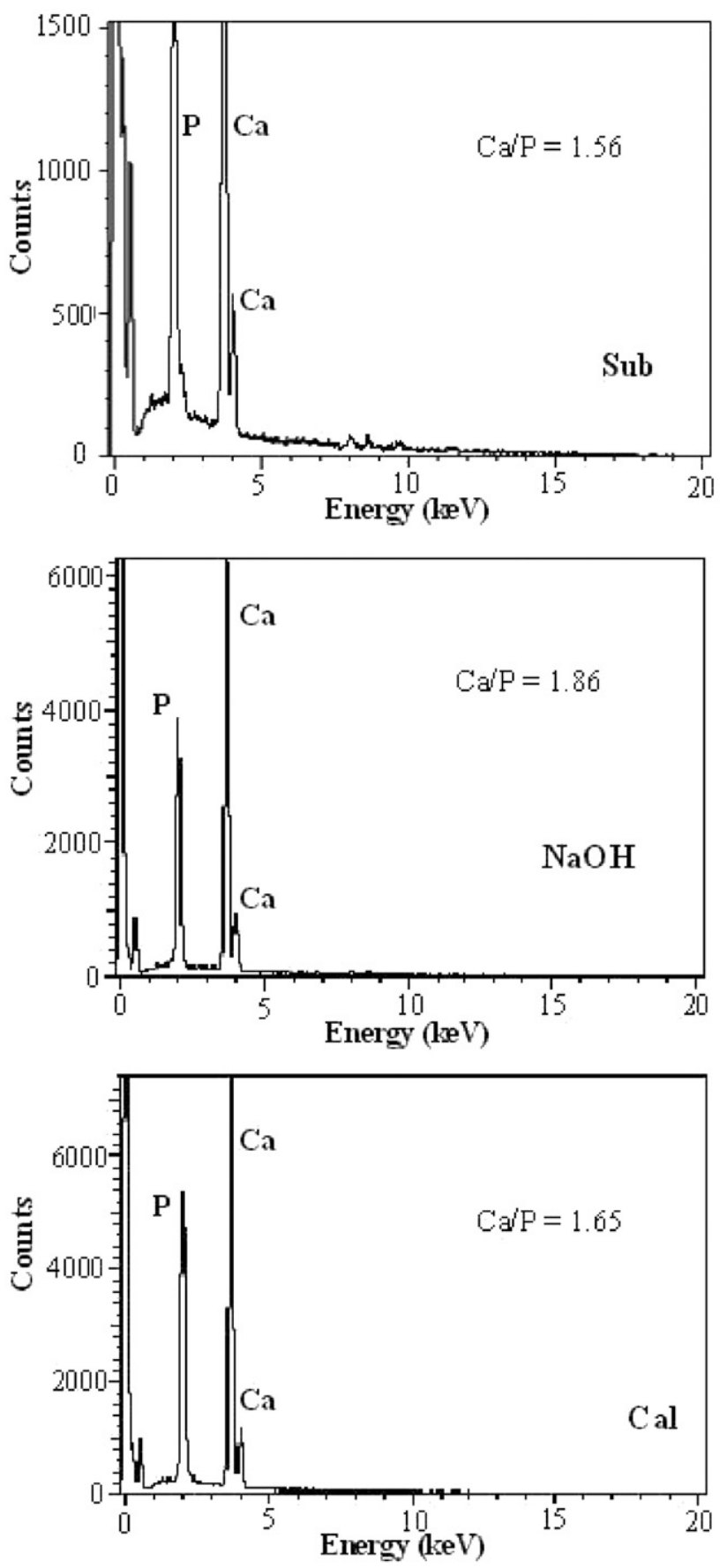

Fig. 6. EDX results for the apatites obtained by subcritical method (Sub), alkaline hydrolysis $(\mathrm{NaOH})$ and thermal process $(\mathrm{Cal})$.

process can be regarded to the tendency of the hydroxyapatite grains to agglomerating and growing up at high temperatures [46]. The final hydroxyapatite powder obtained by the subcritical water extraction process consists of nano flakes as indicated by the FE SEM (Fig. 9A). While, the alkaline hydrolysis produces apatites with almost nanorod shape as shown in Figs. 8A and 9B.

\section{Conclusion}

The proposed and the traditional processes can be exploited to extract natural biological apatite bioceramic from the bovine bone biowaste. Subcritical water extraction has the advantage of producing carbonated hydroxyapatite which is preferred in the biomedical applications. The alkaline hydrothermal process also relatively maintains the carbonate ion present in the biological apatite but less than the subcritical water method. The thermal process almost produces hydroxyapatite carbonate-free. The apatite obtained by the thermal process has higher particle size and better crystallinity than the proposed processes. The alkaline hydrothermal process produces relatively better nanoparticle shape (nanorods) than the other two processes.

\section{Acknowledgement}

This work is supported by the grant of Post-Doc. Program Chonbuk National University (CNU) (the second-half term of 2006) Chonbuk National University, Jeonju 561-756, Republic of Korea.

\section{References}

[1] J.C. Elliott, Structure and Chemistry of the Apatites and other Calcium Orthophosphates, Elsevier, Amsterdam, 1994.

[2] S.F. Hulber, J.C. Bokros, L.L. Hench, J. Wilson, G. Heimke, Ceramics in clinical applications: past, present and future, in: P. Vincenzini (Ed.), High Tech Ceramics, Elsevier, Amsterdam, 1987, pp. 189-213.

[3] K.C.B. Yeong, J. Wang, S.C. Ng, Biomaterials 22 (20) (2001) 2705

[4] T. Isobe, S. Nakamura, R. Nemoto, M. Senna, H. Sfihi, J. Phys. Chem. B 106 (2002) 5169.

[5] J. Liu, K. Li, H. Wang, M. Zhu, H. Yan, Chem. Phys. Lett. 396 (2004) 429.

[6] P. Parhia, A. Ramanan, A.R. Ray, Mater. Lett. 58 (2004) 3610.

[7] S. Sarig, F. Kahana, J. Cryst. Growth 237-239 (2002) 55.

[8] G. Bezzi, G. Celotti, E. Landi, T.M.G. La Torretta, I. Sopyan, A. Tampieri, Mater. Chem. Phys. 78 (2003) 816.

[9] I.S. Kim, P.N. Kumta, Mater. Sci. Eng. B 111 (2004) 232.

[10] D.M. Liu, T. Troczynski, W.J. Tseng, Biomaterials 22 (2001) 1721.

[11] D.M. Liu, T. Troczynski, W.J. Tseng, Biomaterials 23 (2002) 1227.

[12] J.L. Xu, K.A. Khor, Z.L. Dong, Y.W. Gu, R. Kumar, P. Cheang, Mater. Sci. Eng. A 374 (2004) 101

[13] Y.X. Pang, X. Bao, J. Eur. Ceram. Soc. 23 (2003) 1697.

[14] J. Liu, X. Ye, H. Wang, M. Zhu, B. Wang, H. Yan, Ceram. Int. 29 (2003) 629.

[15] M. Yoshimura, P. Sujaridworakun, F. Koh, T. Fujiwara, D. Pongkao, A. Ahniyaz Mater. Sci. Eng. C 24 (2004) 521.

[16] L. Yan, Y. Li, Z.X. Deng, J. Zhuang, X. Sun, Int. J. Inorg. Mater 3 (2001) 633.

[17] W.J. Shih, Y.F. Chen, M.C. Wang, M.H. Hon, J. Cryst. Growth 270 (2004) 211

[18] G. Guo, Y. Sun, Z. Wang, H. Guo, Ceram. Int. 31 (2005) 869.

[19] G.C. Koumoulidis, A.P. Katsoulidis, A.K. Ladavos, P.J. Pomonis, C.C. Trapalis, A.T Sdoukos, T.C. Vaimakis, J. Colloid Interface Sci. 259 (2003) 254.

[20] K. Sonoda, T. Furuzono, D. Walsh, K. Sato, J. Tanaka, Solid State Ionics 151 (2002) 321.

[21] S. Bose, S.K. Saha, Chem. Mater. 15 (2003) 4464.

[22] A. Antonakos, E. Liarokapis, T. Leventouri, Biomaterials 28 (2007) 3043.

[23] J.C. Elliot, Structure and Chemistry of the Apatites and other Calcium Orthophosphates, Elsevier, Amsterdam, 1994 and references therein.

[24] M. Ozawa, S. Suzuki, J. Am. Ceram. Soc. 85 (2002) 1315.

[25] S. Joschek, B. Nies, R. Krotz, A. Göpferich, Biomaterials 21 (2000) 1645.

[26] L. Xiaoying, F. Yongbin, G. Dachun, C. Wei, Key Eng. Mater. 342-343 (2007) 213.

[27] T. Leventouri, B.C. Chakoumakos, N. Papanearchou, V. Perdikatsis, J. Mater. Res. 16 (2001) 2600.

[28] L. Samuel, M.D. Turek, J.B. Lippincott, Orthopaedics: Principles and Appications, 2nd Edition) p. 113 and 136, 1985.

[29] A. Gousterova, M. Nustorova, I. Goshev, P. Christov, D. Braikova, K. Tishinov, T. Haertle, P. Nedkov, 17 (2003) 140

[30] A. Gousterova, D. Braikova, I. Goshev, P. Christov, K. Tishinov, E. Vasileva-Tonkova T. Haertle, P. Nedkov, Lett. Appl. Microbiol. 40 (2005) 335.

[31] Y. Yang, M. Belghazi, A. Lagadec, D.J. Miller, S.B. Hawthorne, J. Chromatogr. A 810 (1998) 149

[32] Colin, H.L. Ho, E. Juan, G. Cacace, Mazza, LWT 40 (2007) 1637.

[33] T. Anekpankul, M. Goto, M. Sasaki, P. Pavasant, A. Shotipruk, Sep. Purif. Technol. 55 (2007) 343.

[34] H. Mohammad Eikani, F. Golmohammad, S. Rowshanzamir, J. Food Eng. 80 (2007) 735.

[35] Ö. Güçlü-Üstündağ, J. Balsevich, G. Mazza, J. Food Eng. 80 (2007) 619.

[36] M. Markovic, J. Res. Natl. Inst. Stand. Technol. 109 (2004) 553.

[37] R.L. Frost, S.J. Mills, M.L. Weier, Spectrochim. Acta, Part A: Mol. Biomol. Spectrosc. $61 \mathrm{~A}(1-2)(2004) 177$

[38] M.E. Fleet, X. Liu, Biomaterials 28 (2007) 916

[39] M. Sivakumar, T.S. Sampath Kumart, K.L. Shantha, K. Panduranga Rao, Biomaterials 17 (1996) 1709

[40] C.M. Lopatin, V. Pizziconi, T.L. Alford, T. Laursen, Thin Solid Films 326 (1998) 227.

[41] JCPDS Card No. 9-432, (1994).

[42] S. Kannan, A. Rebelo, A.F. Lemos, A. Barba, J.M.F. Ferreir, J. Eur. Ceram. Soc 27 (2007) 2287.

[43] M.C. Changa, J. Tanaka, Biomaterials 23 (2002) 4811.

[44] S. Masmoudia, A. Larbot, H. El Feki, R. Ben Amarm, Desalination 190 (2006) 89.

[45] Marion D. Francis, Ned C. Webb, Calcif. Tissue Res. 6 (1971) 335.

[46] Y. Han, S. Li, X. Wang, L. Jia, J. He, Mater. Res. Bull. 42 (2007) 1169. 


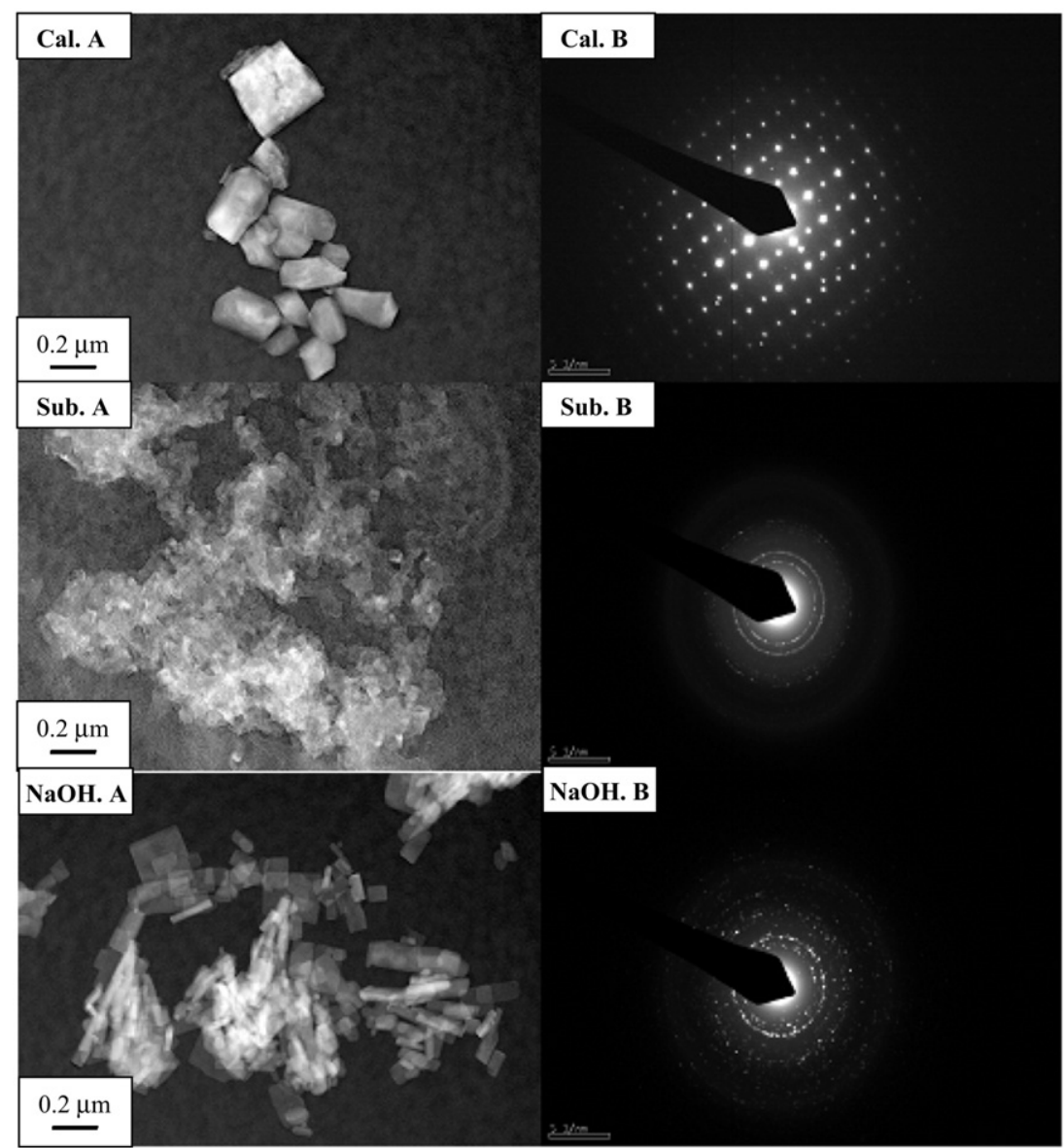

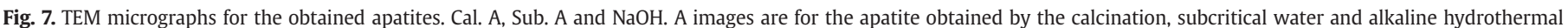
processes, respectively. Cal. B, Sub. B and $\mathrm{NaOH}$. B are selected area electron diffraction patterns.

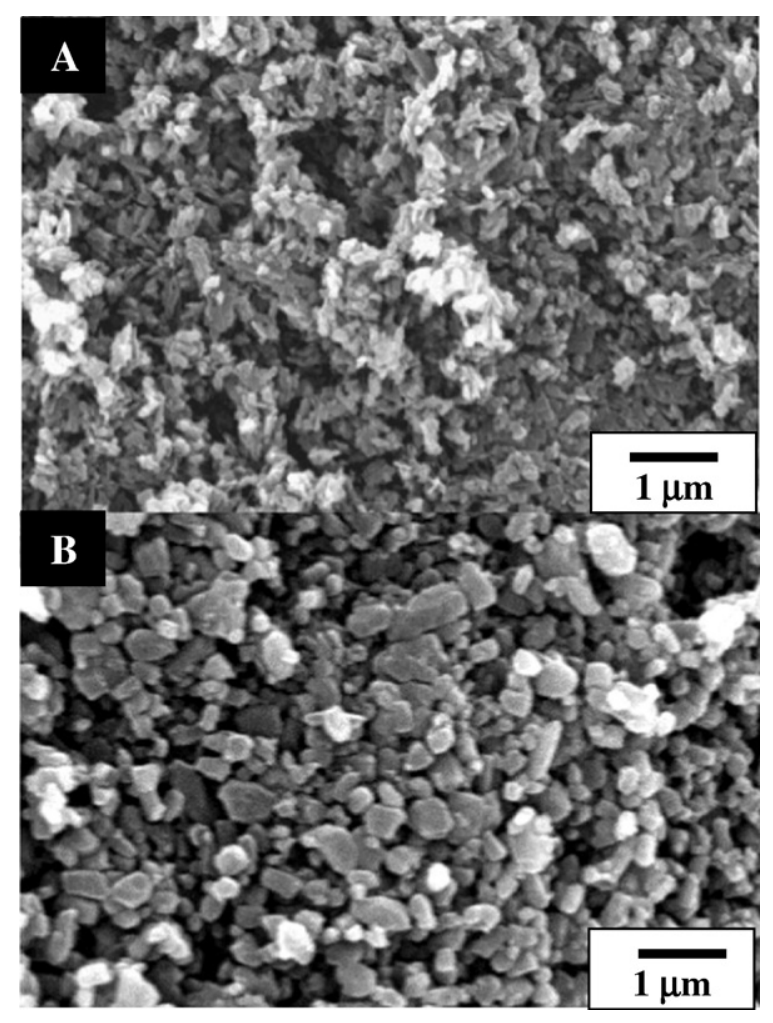

Fig. 8. SEM images for hydroxyapatite obtained by (A) alkaline hydrothermal process and (B) calcination process.

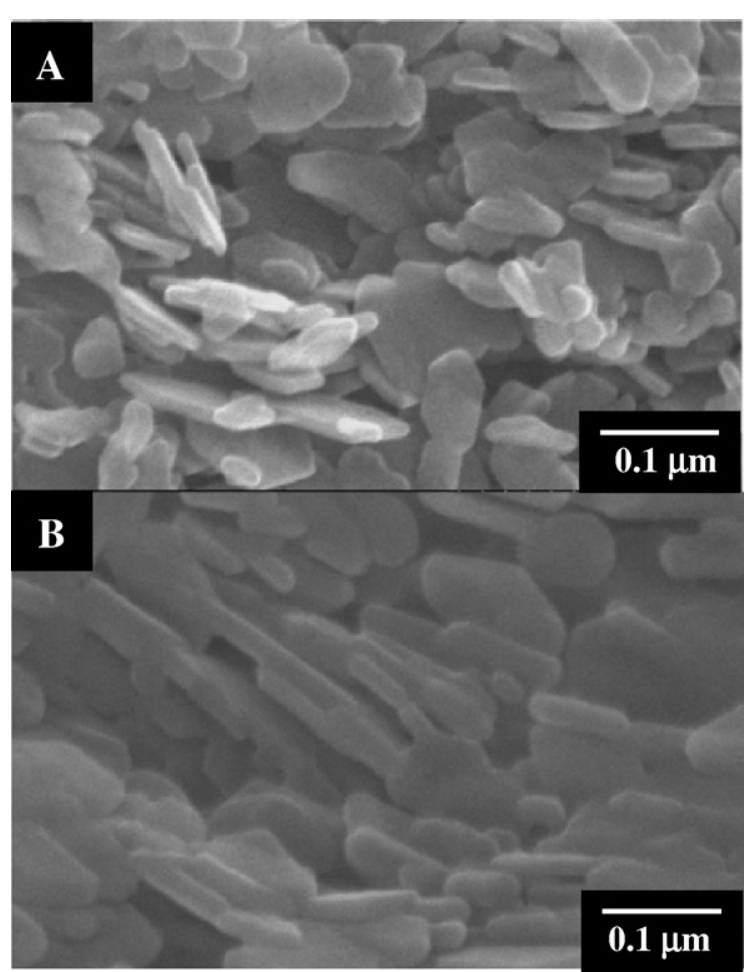

Fig. 9. FE SEM images for hydroxyapatite obtained by (A) subcritical water process and (B) alkaline hydrothermal process. 